\title{
Patient's attitude and knowledge towards the usage of barrier technique by orthodontists
}

\author{
Tarulatha R Shyagali, Deepak P Bhayya
}

Department of orthodontics and dentofacial orthopedics, Darshan dental college and hospital, Loyara, Udaipur.

\begin{abstract}
This article assesses patients' attitudes and knowledge regarding the use of barrier technique by orthodontists. One hundred orthodontic patients, age 15-20 years, who visited the department of orthodontics, Darshan dental college, Udaipur, were randomly selected and asked to complete a questionnaire of ten questions related to the usage of barrier technique by orthodontists. The collected data were subjected to descriptive statistical analysis, and chi-square tests were performed to evaluate the difference between genders. Ninetysix percent of patients felt orthodontists should wear gloves, $98 \%$ wanted their orthodontist to wear a mouth mask and 58\% wanted the orthodontist to wear protective glasses during the treatment procedure. Eighty-eight percent of patients refused treatment by orthodontists who were not wearing gloves and $75 \%$ wanted the gloves to be changed for each patient. A significant difference was seen between females and males in their attitude regarding barrier technique used by the orthodontist. A high level of awareness was seen in the present group of orthodontic patients and this should alert orthodontists to review their infection control strategies.
\end{abstract}

\section{Key words}

Orthodontics; Gloves, protective; Infectious diseases, transmission, professional-to-patient, prevention and control; patient satisfaction

\section{Corresponding Author}

Dr Tarulatha R Shyagali MDS

Staff qutraus no:6, Darshan dental college and hospital campus, Loyara, Udaipur

E mail: drdeepu20@yahoo.com,drdeepu20@rediff.com 


\section{Introduction}

Every patient has the right to receive the best care and treatment whenever he/she comes to hospital regardless of his or her health status at the time of the hospital visit. Wide spread increase in contagious diseases, e.g., human immunodeficiency virus, hepatitis, H1N1 (swine flu), cytomegalovirus and herpes simplex, pose an increased risk of cross contamination to orthodontists. The risk is not only pertinent to them and the patient, but to their immediate family and friends. Wearing gloves is one of the measures to overcome contamination; it's been advocated by many authorities, including the authors. ${ }^{1-6}$ Glove wearing not only assures patients regarding the infection awareness of the dentist; it also reduces the risk of cross infection from patient to the dentist and from patient to patient. ${ }^{6}$ It has also been reported that finger nails are a potential contamination site owing to the difficulty in removing contaminated material from the hands, particularly the subungual and nail fold areas. ${ }^{8,9}$

Another method of protection is wearing a mouth mask, which may become a source of infection if worn for a long time. This may occur if touched by contaminated hands, and if it becomes wet with the exhaled air. ${ }^{2,10}$ To overcome this, the operator is supposed to use US National Institute for Occupational Safety and Health (NIOSH) certified masks. ${ }^{11}$ Masks which were used earlier were made of woven cotton fabric; these are now replaced with spun-bonded polypropylene masks known for their superior filtration capabalities. ${ }^{12}$

In earlier articles on infection control it has been mentioned that orthodontists along with the general dentist avoided wearing gloves for various reasons. These include, amongst others, operating difficulties, reduced sensation, low risk of infection and skin reactions. ${ }^{13}$ However, this might not be applicable in the present era as both dentist and orthodontist are more aware of infection prevention protocols. Some authors have considered that a cross infection regime for orthodontists need not be as rigorous as those required in general dental practice. ${ }^{14,15}$ This is a questionable statement, since orthodontists are as vulnerable as general dentists for transmission of infection due to procedures such as wire bending, banding, ligature wire usage etc. An accidental piercing of a wire might harbour multiple infectious agents, which can cause a variety of infections. Surprisingly, these are the same procedures that restrain an orthodontist from using gloves, because wearing gloves has perceived limitations such as; loss of tactile sensation, limited finger movements, and inconvenience during wire bending. ${ }^{16-20}$ However, Cheng et al. in their study reported that bending the round wire was more convenient without gloved hands and that other routine orthodontic procedures can be handled with gloves efficiently. ${ }^{21}$ Studies have shown that wearing gloves by dentists was expected by patients and the level of gloves usage by orthodontists was less than that of the general practitioner. ${ }^{17,20,22-24}$

Previous studies have addressed the attitude of orthodontists to glove use, while some have evaluated the patient's attitude towards glove use by orthodontists. None of the studies included the other commonly used barrier techniques. There is also a scarcity of literature pertaining to the barrier technique usage in the developing countries. The main aim of this study is to assess the patient's attitude and knowledge towards the use of different barrier techniques by the orthodontist.

\section{Materials and methods}

Over a period of one month, 100 patients (50 females and 50 males) visiting the department of orthodontics, Darshan dental college, Udaipur (Rajasthan, India), for the first time were randomly selected for the study. All the orthodontists and the residents followed strict infection control regimes as per the US Centre for Disease Control and Prevention (CDC) recommendations. The purpose of the study was to gather knowledge and attitude of the patients towards the infection control regimes. The subjects were 1520 years of age, the mean age was $17 \pm 2$ years. Using information from earlier studies, ${ }^{25,26}$ a questionnaire with ten questions, related to patient's attitude towards infection control practices used by orthodontists, was designed by the expert panel that included experienced orthodontists. General information, such as age, sex, residential address, educational qualification and occupation, was also collected. The questionnaire was printed both in English and native language (Hindi) for convenience of the patients. 
A pilot study was completed with 20 patients to confirm the clarity of the framed questions. Patients were informed regarding the purpose of the study and the questionnaires were distributed. They were asked to fill them out in the department itself to reduce outside influence. All the participants were asked to complete a consent form. If the subject was minor the parents/guardians were asked to sign the consent form. Collected data were fed into statistical software, SPPS 15. Descriptive analysis was done to calculate percentages and Chi square tests were performed to judge the difference between genders.

\section{Results}

Figures 1-6 illustrates the knowledge and attitudes of the patients regarding usage of different barrier techniques by the orthodontist. Ninety-six percent of the subjects wanted their orthodontist to wear gloves and $98 \%$ of subjects wanted orthodontists to wear a mouth mask. The majority of subjects believed that wearing mouth mask and gloves will protect both orthodontist and patients from infection.

Seventy-one percent of subjects thought that dental assistants should also wear gloves. The attitude of the subjects was not the same for wearing protective glasses; only 58 percent of them believed that orthodontists should wear protective glasses. Eighty eight percent of the subjects refused to go to an orthodontist who doesn't wear gloves.

When the purpose of wearing gloves was considered, 38 percent of subjects thought wearing gloves will prevent transmission of infection from patient to orthodontist. A majority of them were satisfied with the type of barrier technique used by the orthodontist. There was no significant difference between male and females, except for satisfaction about barrier techniques. Greater number of females were not satisfied with the barrier technique used by the orthodontist.

\section{Discussion}

In spite of the fact that many authorities have recommended a comprehensive guideline on infection control, orthodontic practitioners are less prudent then general practitioners with regard to infection control measures. ${ }^{27}$ However, the attitude of orthodontic patients toward usage of barrier techniques by the orthodontist is more important; therefore this study aimed to explore the orthodontic patient's view toward usage of barrier technique by the orthodontist.

A majority of patients (96\%) in this study wanted their orthodontist to wear gloves, which indicates a high level of awareness among patients. Only $4 \%$ of the

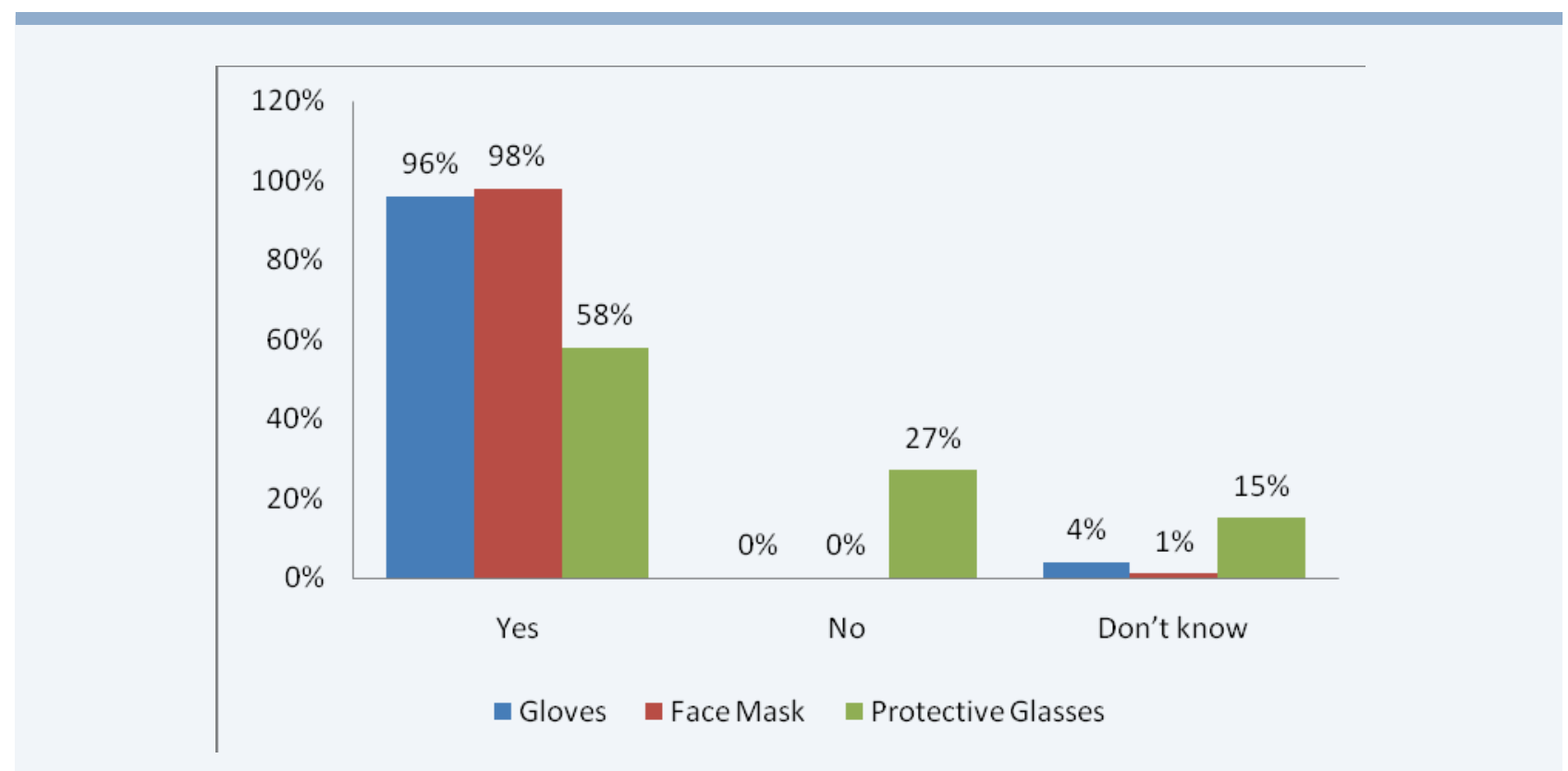

Figure 1. Patient's attitude towards the use of different protective barriers by Orthodontist. 


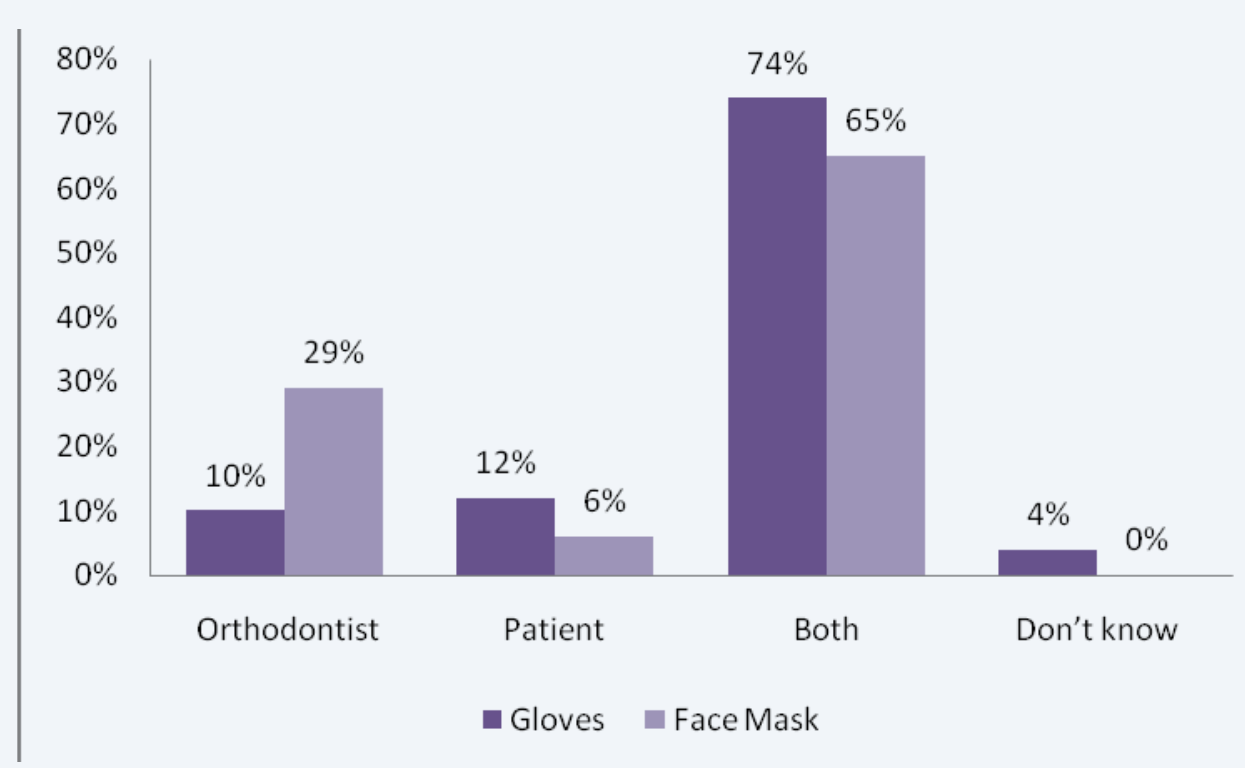

Figure 2. Patient's opinion on whether gloves are worn to protect orthodontist or patient

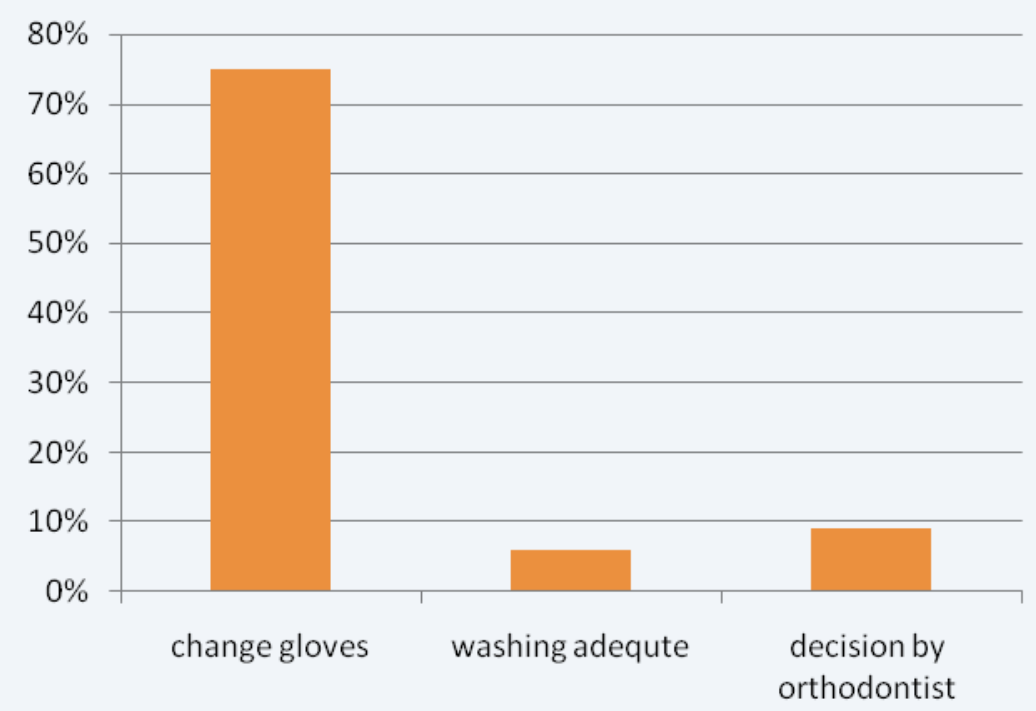

Figure 3. Patient's opinion on whether an orthodontist should change gloves between patients or washing is sufficient.

patients were not sure whether gloves were necessary or not. Similar results $(94.9 \%)$ were reported by AlMoherat et al. who evaluated the level of awareness in Jordanian orthodontic patients to glove use by orthodontist. ${ }^{26}$ A comparatively high level (97\%) of awareness was reported in Ireland..$^{25}$ In contrast a study on German orthodontists, showed that 16.9 percent of surveyed individuals considered wearing gloves was absolute necessary. ${ }^{24}$
A high percentage $(88 \%)$ of patients felt that they would not go to an orthodontist who didn't wear gloves; this coincided with the results of previous studies. ${ }^{25,26}$ Considering the percentage of patients who wanted the orthodontist to wear gloves, this is not surprising. However, the percentage of orthodontists wearing gloves in their routine practice varies greatly in different countries. For example, 


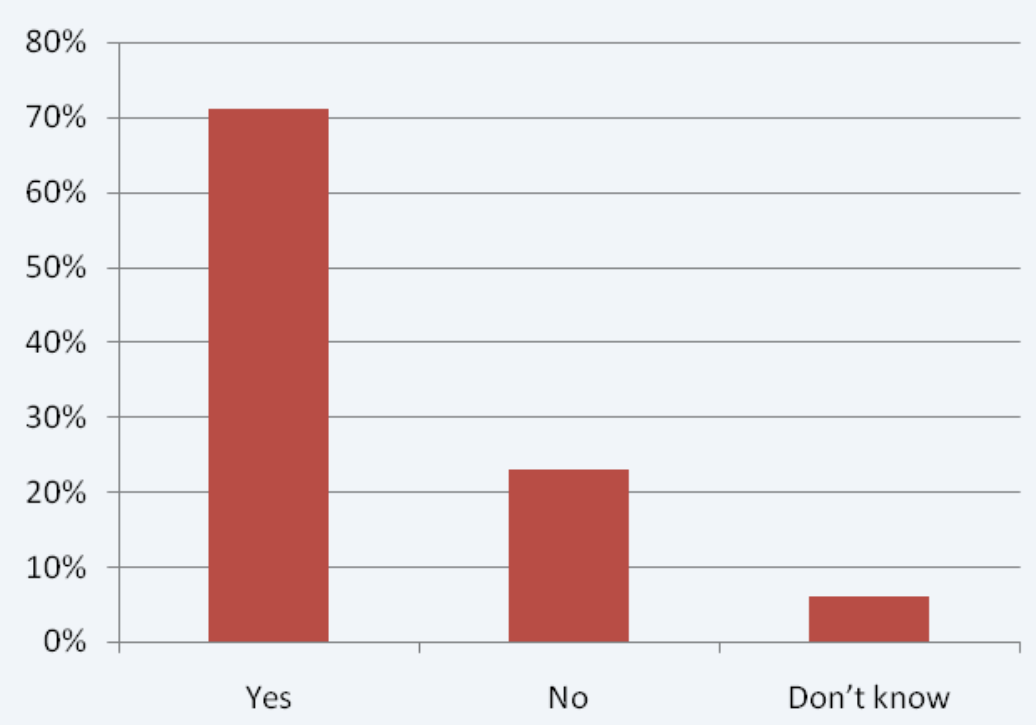

Figure 4. Patient's opinion on whether dental assistant should wear gloves or not.

only $39 \%$ of orthodontists used gloves routinely in England and Wales during 1989. ${ }^{27}$ By 1994 the usage of gloves was routine in $60 \%$ of the orthodontists in the same locality. ${ }^{23}$ However, in Ontario, $85 \%$ of the orthodontists used gloves routinely, ${ }^{28}$ the figures were similar for California orthodontists, ${ }^{20}$ whereas in Turkey only $48.5 \%$ of orthodontist used gloves. ${ }^{29}$ The available data on glove usage by orthodontists displays a geographical variability, which seems to be indirectly influenced by cultural differences and the educational level of the orthodontist. Nevertheless, there are no available data to prove the same. In a recent study by Doll et al. on the efficacy of protection by gloves during orthodontic therapy, they found that wearing single gloves for treating an infected patient won't be effective due to the high percentage of perforations reported, so they suggest wearing 2 pairs of gloves when treating an infected patient. ${ }^{30}$

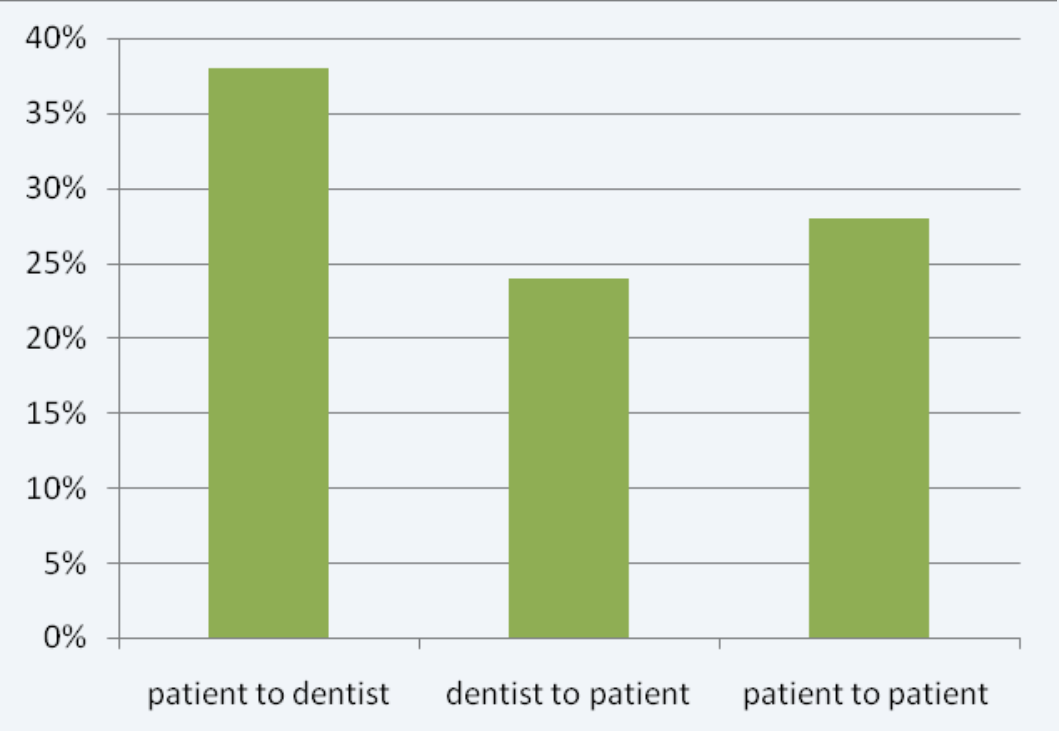

Figure 5. Knowledge regarding the purpose of wearing gloves with regards to transmission of infection 


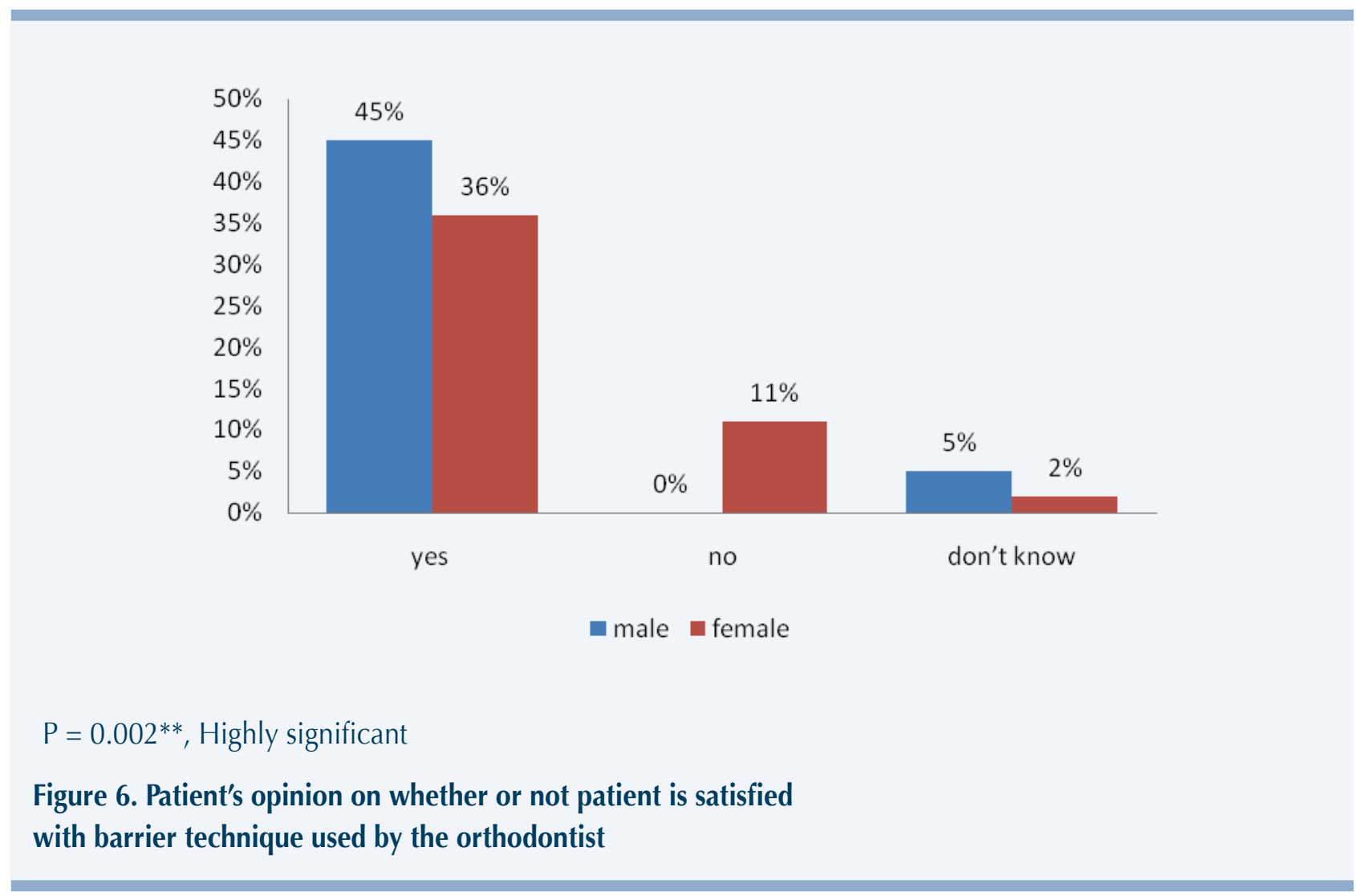

In the previous studies, patients were of the opinion that glove usage will protect both the orthodontist and the patient $(89.4 \%$ and $94 \%))^{25,26}$ The results of this study indicate only $74 \%$ of patients thought that glove use will protect both orthodontists and patients. Ten percent of them believe that glove wear will protect the orthodontist only and $12 \%$ reported that glove wear will protect patients only. This shows that, even though infection control awareness is high, the knowledge seems to be superficial. In contrast, Bowden et al. reported $31 \%$ of patients believe that glove use will protect the dentist only, ${ }^{31}$ and Otuyemi et al. also reported similar results. ${ }^{32}$

A high level of awareness was again proved by the fact that only $6 \%$ of patients didn't mind if their orthodontist used the same gloves after washing in between patients. However, this percentage was quite high in comparison to the report of Kearns et al. who reported that only $2.5 \%$ of patients felt that washing gloved hands will be enough. ${ }^{18}$ Such favourable results were reported in earlier studies. $7,25,32,33$

Wearing of gloves by the dental assistant was considered necessary by 71 percent of patients, owing to the fact that dental assistants assist the orthodontist during bracket positioning, band placement, cementation, wire changing, etc, they believed that it makes sense for the dental assistant to wear gloves. However, in the previous survey on the orthodontists of England and Wales, only $22 \%$ of dental assistant wore gloves all the time. ${ }^{34}$

A high percentage of patients felt that orthodontists should wear a mouth mask, which equalled the percentage of patients who wanted the orthodontist to wear gloves. This finding once again highlights the high level of awareness among patients. An overwhelming percent $(65 \%)$ of them felt it will protect both orthodontist and patients. This percentage was less when compared to glove use, where 74 percent of them feel glove wear will protect both. In the previous study, around 77 percent of the patients preferred their dentist to wear a mouth mask. However, only 12 percent of orthodontists wore a mask in a study by Burke et al. ${ }^{34}$

Croig and colleagues in their study mention that a mask worn for more than 20 minutes will be a potential harbour of micro-organisms and it is better to work unmasked then to wear the same mask for a longer duration. ${ }^{10}$ 
Nearly $81 \%$ of patients were satisfied with the barrier techniques followed by their orthodontist, however there existed a significant difference in the satisfaction level between females and males; satisfied females were less in comparison to satisfied males.

A mixed response was obtained for one question - what was the purpose behind wearing the mouth mask. Few patients (24\%) thought it is to prevent the transmission of infection from orthodontist to patient, $28 \%$ of them thought it is to prevent the transmission from patient to patient, and the rest, $38 \%$, felt it is to prevent infection spread from patient to orthodontist. Wearing a protective glass by the orthodontist was considered unnecessary by $27 \%$ of the patients. However, a study by Shulman et al. on patients' attitude on infection control showed that $54.1 \%$ of them preferred their dentist to wear protective glasses when performing a treatment. ${ }^{35}$ In a survey conducted by Askarian et al. amongst Iranian dentist and dental students on their knowledge, attitude and practice of infection control, they reported that the surveyed subjects had a high level of knowledge and attitude. However, they didn't adhere strictly to infection control guidelines. ${ }^{36}$

\section{Conclusion}

The following conclusions can be drawn from this study, a high level of infection control awareness was seen in this particular group of patients.

Female patients were less satisfied than their male counterparts with regard to barrier techniques used by their orthodontist.

In this particular population, even though awareness about infection control was high, the knowledge seems to be superficial. This implies the need for the organization of public health education programmes in this area. The time has come for orthodontists who are not using the recommended barrier technique protocol to evaluate their infection control strategies, for the improvement of their own and the patient's life, leading towards disease free and healthy families.

\section{References}

1. CDC. Recommended infection-control practices for dentistry, 1993. Morbidity And Mortality Weekly Report 1993; 42: RR8.

2. Kohn WG, Collins AS, Cleveland JL, Harte JA, Eklund KJ, Malvitz DM. Guidelines for infection control in dental healthcare settings - 2003. Morbidity And Mortality Weekly Report 2003; 52: 1-61.

3. British Dental Association. Guide to blood borne viruses and the control of cross infection in dentistry. BDA, London. 1987.

4. Rustage KJ, Rothwell PS, Brook IM. Evaluation of a dedicated dental procedure glove for clinical dentistry. Br Dent / 1987; 103: 193-195. http://dx.doi.org/10.1038/sj.bdj.4806240

5. Olnsted RN. Reusable gloves. I Am Dent Assoc 1978; 114: 14-15.

6. Crawford TJ. State of the art practical infection control in dentistry. J Am Dent Assoc 1985; 110: 629-633.

7. Burke FJT, Baggett FJ, Willson NHF. Patient attitude to wearing of gloves by dentists. Dental Update 1991; 18: 261-264.

8. Burke FJT, Wilson NHF, Bogge HFJ. Glove wearing by dental surgery assistants. Dental Update 1993; 20: 385-387.

9. Allen AL, Organ RJ. Occult blood accumulation under the finger nails. A mechanism for the spread of blood borne infection. J Am Dent Assoc 1982; 105: 455-459.

10. Croig DC, Quale AA. The efficiency of mouth masks. Br Dent J 1985; 158: 87-90.

11. CDC. Guidelines for preventing the transmission of Mycobacterium tuberculosis in health-care facilities. Morbidity and Mortality Weekly Report 1994; 43: RR-13.

12. Board on Health Sciences Policy. Characteristics of Respirators and Medical Masks In Reusability of Facemasks during an Influenza Pandemic: Facing the Flu. The National Academies Press, Washington DC 2006; 22-41.

13. Fein S. Infection control in orthodontic practice. Am J Orthod Dentofacial Orthop 1989; 95: 84. http://dx.doi. org/10.1016/0889-5406(89)90140-6

14. Usiskin LA. Hand in glove with the orthodontist? Br Dent J 1989; 16: 49-50.

15. Walsh LJ, Lange P, Savage N. Factors influencing the wearing of protective gloves in general dental practice. Gen Dent 1995; 26: 203-209.

16. Stranbach H, Biddle P. A pragmatic approach to asepsis in orthodontic office. Angle Ortho 1986; 50: 63-66.

17. Evans R. Acceptance of recommended cross-infection in the United Kingdom. Br J Orthod 1989: 16: 189-194.

18. Cooley RL, McCourt JW, Barnwell S. Evaluation of gloves for orthodontic use. J Clin Orthod 1989; 23: 30-34.

19. Davis D, BeGole EA. Compliance with infection control procedures among Illinois orthodontists. Am / Orthod Dentofacial Orthop 1998; 113(6): 647-654. http://dx.doi. org/10.1016/S0889-5406(98)70225-2

20. Woo J, Anderson R, Maguire B, Gerbert B. Compliance with infection control procedures among Californian orthodontists. Am J Orthod Dentofacial Orthop 1992; 102: 68-75. http:// dx.doi.org/10.1016/0889-5406(92)70016-4

21. Cheng HS, Lee SY, Chou HY. The Factors influencing wearing of protective gloves in orthodontic practice. Eur / Orthod 2005; 27: 64-71. http://dx.doi.org/10.1093/ejo/cjh074

22. Cash RG. Sterilization and disinfection procedures: a survey of Georgia orthodontist. J Clin Orthod 1988; 22: 22-28.

23. Burke FJT, Wilson NHF, Cheung S-W, Shaw WC. Glove use by orthodontist in England and Wales: changes since 1989 and comparison with general dental practitioners. Eur / Orthod 1994; 16: 241-244. 
24. Cha BK, Brinkman PG, Miethke RR. Survey of acceptance of rubber gloves for orthodontic treatment in Germany. Eur J Orthod 1994; 16: 442-443.

25. Kearns HPO, Burke FJT. Patient attitudes to glove use by orthodontists. Br Dent / 1998; 25: 127-129.

26. Al-Moherat F, Al-Warawreh AM, Khresat HM. Patient's attitude to wearing of gloves by orthodontists. Pakistan oral \& dental journal 2008; 28(1): 75-78.

27. Burke FJT, Wilson NHF, Wastell DG, Cheung SW. Glove use in clinical practice: a survey of 2000 dentists in England and Wales. Br Dent / 1991; 171: 123-132. http://dx.doi. org/10.1038/sj.bdj.4807635

28. McCarthy GM, Mamandras AH, MacDonald JK. Infection control in the orthodontic office in Canada. Am / Orthod Dentofacial Orthop 1997; 112(3): 275-281. http://dx.doi. org/10.1016/S0889-5406(97)70256-7

29. Sa $\square$ lam AM, Sarikaya N. Evaluation of infection-control practices by orthodontists in Turkey. Quintessence Int 2004; 35(1): 61-66.

30. Doll MG, Zentner A, Balan R, Sergl GH. Efficacy of protection by latex gloves during orthodontic therapy. J Orofac Orthop/ Fortschr Kieferorthop 2006; 61: 80-90.
31. Bowden JR, Scully C, Bell CJ, Levers H. Cross-infection control: attitude of patients toward wearing of gloves and masks by dentist in United Kingdom in 1987. Oral Surg Oral Med Oral Pathol 1989; 67: 45-48. http://dx.doi. org/10.1016/0030-4220(89)90301-0

32. Otuyemi OD, Oginni EO, Ogunbodede FO, Olusiie AO. Patients' attitude to wearing of gloves by dentists in Nigeria. East Afri Med / 2001; 78: 220-222. http://dx.doi.org/10.4314/ eamj.v78i4.9068

33. Kerans HPO, Burke FJT, Mccarton. Patient attitudes to glove use by dentists. $\operatorname{Br}$ Dent J 1998; 185: 87-89. http://dx.doi. org/10.1038/sj.bdj.4809734

34. Burke FJT, Wilson NHF, Shaw WC, Cheung SW. Glove use by orthodontists: results of a survey in England and Wales. Eur J Orthod 1992; 14: 246-251.

35. Shulman ER, Brehm WT. Dental clinical attire and infectioncontrol procedures patients' attitudes. J Am Dent Assoc 2001; 132(4): 508-516.

36. Askarian M, Assadian O. Infection control practices among dental professionals in Shiraz dentistry school, Iran. Archives of Iranian Medicine 2009; 12(1): 48-51. 